\title{
Model Pembelajaran Discovery Learning Pada Mata Pelajaran Bahasa Inggris Untuk Meningkatkan Hasil Belajar Pada Aspek Berbicara Materi Descriptive Text
}

\author{
Suryono ${ }^{1}$ \\ 'SMK Negeri 2 Rangkasbitung, \\ Rangkasbitung, Indonesia \\ email: syarifsuryono@gmail.com
}

\begin{abstract}
Abstrak
Masalah pokok yang diangkat dalam Penelitian Tindakan Kelas ini adalah rendahnya hasil belajar bahasa Inggris yang dicapai siswa kelas X. APH.2 SMK Negeri 2 rangkasbitung pada aspek berbicara dalam bahasa Inggris. Penelitian ini dilakukan di SMK Negeri 2 rangkasbitung pada kelas X. APH.2 Semester Ganjil tahun pelajaran 2018/2019 dengan jumlah siswa sebanyak 36 orang. Penelitian ini dilakukan dalam dua siklus, tiap siklus dalam penelitian meliputi empat langkah yaitu (1) perencanaan (planning), (2) pelaksanaan (acting), (3) observasi (observing), (4) refleksi (reflecting). Hasil Penelitian yang diperoleh dalam penelitian ini adalah: 1) Hasil pada siklus I nilai rata - rata 79, 2) Ketuntasan Belajar pada siklus I adalah $78 \%$, 3) Hasil pada siklus II nilai rata-rata 79, dan 4) Ketuntasan Belajar pada siklus II adalah $100 \%$. Berdasarkan data penelitian dan pembahasan dapat diambil kesimpulan bahwa dengan menerapkan model pembelajaran Discovery Learning pada mata pelajaran bahasa inggrius dapat meningkatkan hasil belajar siswa kelas X APH.2 Semester ganjil SMK Negeri 2 Rangkasbitung tahun pelajaran 2018/2019.
\end{abstract}

Kata Kunci: Prestasi Belajar Agama Hindu, Model Quick on The Draw.

\begin{abstract}
The main problem raised in this Classroom Action Research is the low English learning outcomes achieved by class X. APH.2 SMK Negeri 2 rangkasbitung in the aspect of speaking in English. This research was conducted at SMK Negeri 2 Rangkasbitung in class X. APH.2 Odd Semester 2018/2019 academic year with a total of 36 students. This research was conducted in two cycles, each cycle in the study includes four steps, namely (1) planning, (2) implementation, (3) observation, (4) reflection. The research results obtained in this study were: 1$)$ The results in the first cycle an average value of 79,2 ) the completeness of learning in the first cycle was $78 \%, 3$ ) the results in the second cycle an average value of 79 , and 4 ) the completeness of learning in cycle II is $100 \%$. Based on research data and discussion, it can be concluded that by applying the Discovery Learning model to English subjects, it can improve the learning outcomes of class X APH students. 2 Odd semester of SMK Negeri 2 Rangkasbitung in the 2018/2019 academic year.
\end{abstract}

Keywords: English Learning Outcomes, Descriptive Text, Model Discovery Learning.

\section{Pendahuluan}

Pembelajaran bahasa inggris di SMK Teknologi dan Non Teknologi, juga Seni dan Pariwisata, memberikan kesan tersendiri bagi Peneliti, karena siswa lebih banyak berkaitan dengan unsur-unsur bidang keahlian yang diikuti oleh siswa. Namun demikian komunikasi dalam bahasa inggris harus tetap terwujud dengan baik dan benar karena setiap program keahlian memerlukan nya. Siswa wajib mengikuti pelajaran bahasa inggris karena tuntutan dari kurikulum yang berlaku. Untuk itu ke wajiban siswa untuk mengikuti pembelajaran bahasa inggris adalah agar lulusannya mampu bersaing di dunia kerja baik di tingkan Nasional

\footnotetext{
*Corresponding author.
}

Received 03 Februari 2020; Accepted 31 July 2020; Available online 1 September 2020 (c) 2020 MPI. All Rights Reserved 
maupun Internasional. Banyak upaya yang dapat dilakukan guru dalam mengajarkan mata pelajaran berbahasa inggris bagi siswa kelas X APH.2 SMK Negeri 2 Rangkasbitung, agar komunikasi dalam bahasa inggris dapat terjalin dengan baik antar siswa dengan siswa bahkan antara siswa dengan guru. Jenis media yang sesuai dapat di manfaatkan oleh siswa dalam berbahasa inggris secara maksimal. Namun hal ini tidaklah demikian bagi siswa kelas X.APH.2 SMK Negeri 2 Rangkasbitung. Siswa Program keahlian APH.2 belum mampu secara optimal dalam merefleksikan pelajaran bahasa inggris dalam aktivitas sehari-hari disekolah dalam bentuk komunikasi baik dengan teman sendiri maupun dengan guru. Kemampuan berbahasa inggis bagi siswa SMK sangat diperlukan untuk menunjang profesi mereka sesuai dengan Program Keahliannya yang mereka pilih dan juga merupakan mata pelajaran wajib yang diikuti oleh siswa.

Pada akhir pembelajarannya siswa diharapkan mampu mengungkapkan makna descriptive text sederhana dalam konteks kehidupan sehari-hari. Berdasarkan hasil tes prasiklus yang dilaksanakan peneliti pada tahap awal Penelitian Tindakan Kelas ini hasil belajar siswa rendah dengan nilai rata-rata 70,4 dan ketuntasan belajar mencapai $28 \%$. Sedangkan standar nilai yang ditentukan sekolah untuk mata pelajaran bahasa Inggris adalah 75 Melihat kondisi demikian Peneliti merasa tergugah untuk melakukan perbaikan-perbaikan melalui Penelitian Tindakan Kelas ini, dengan mewujudkan keterampilan proses dan pembelajaran yang menekankan pada peran aktif, melalui penerapan model pembelajaran Discovery Learning sehingga mampu mestimulus siswa untuk lebih aktif dan lebih semangat dalam belajar bahasa inggris Atas dasar kenyataan yang demikian, maka perlu dicari alternative lainnya dengan melakukan inovasi-inovasi baik dalam metode penyampaian maupun penggunaan fasilitas media serta pemanfaatan komputer sebagai media untuk meningkatkan hasil belajar bahasa Inggris bagi siswa. Berkaitan dengan hal tersebut diatas maka dalam pelaksanaan Penelitian Tindakan Kelas ini Peneliti mengangkat mata pelajaran bahasa Inggris dengan materi discriptive Text. Maka judul Penelitian Tindakan Kelas ini adalah "Penerapan Model Pembelajaran Discovery Learning Pada Mata Pelajaran Bahasa Inggris Untuk Meningkatkan Hasil Belajar Pada Aspek Berbicara Materi Descriptive Text Bagi Siswa Kelas X. APH.2 Semester Ganjil SMK Negeri 2 Rangkasbitung Tahun Pelajaran 2018/2019.

\section{Metode Penelitian}

Penelitian ini adalah Penelitian Tindakan kelas, maka metode yang digunakan untuk mengolah data adalah metoda deskriptif analisis hasil Penelitian Tindakan Kelas (PTK), yaitu studi yang digunakan untuk mengumpulkan data, mendeskripsikan, mengolah, menganalisa, menafsirkan dan menyimpulkan data sehingga diperoleh gambaran yang sistematis.

Penelitian Ini dilakukan di SMK Negeri 2 Rangkasbitung Tahun Pelajaran 2018/2019 dengan Subjek Penelitian sebanyak 36 orang siswa kelas X.APH2 Semester Ganjil. Kelas itu dijadikan sebagai subjek penelitian karena rata-rata hasil tes awal (Pra siklus), adalah rendah/dibawah KKM yang ditentukan sekolah yakni 75, sedangkan hasil prasiklus yang dicapai siswa dengan nilai rata-rata adalah.70,4 dengan ketuntasan belajar mencapai $28 \%$, sehingga berdasarkan kondisi demikian peneliti terdorong untuk melakukan perbaikan melalui penelitian ini, agar hasil belajar siswa dapat ditingkatkan.

Adapun prosedur yang diterapkan dalam Penelitian Tindakan kelas ini seperti yang digambarkan di bawah ini. 


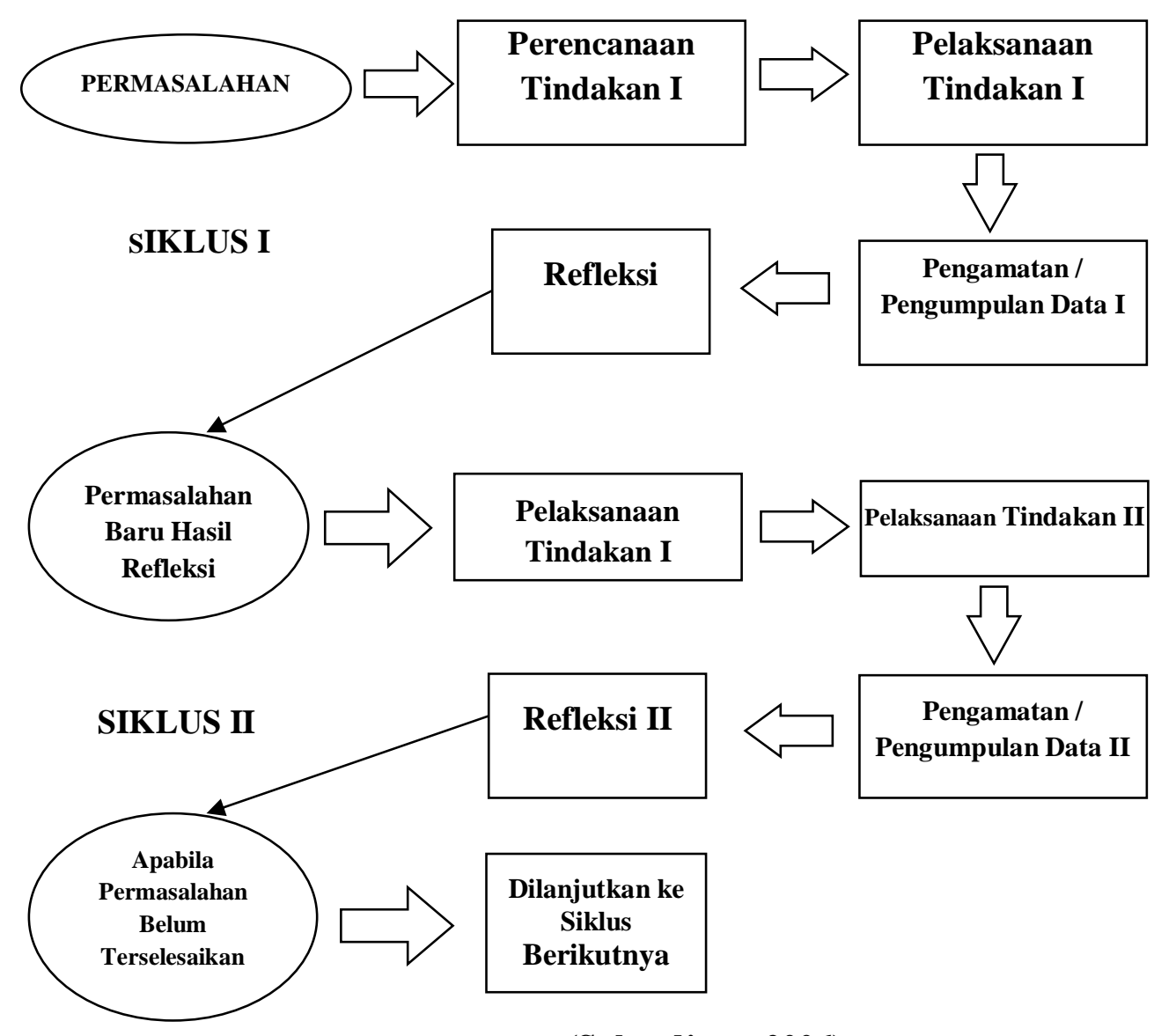

(Suhardjono, 2006)

Gambar 01. Prosedur Penelitian

Keterangan dari gambar prosedur teresebut diatas dapat diuraikan seperti yang tersajikan pada halaman berikut:

\section{SIKLUS I \\ Perencanaan}

Pada tahapan ini peneliti/guru membuat rancangan tentang focus permasalahan yang perlu mendapatkan perhatian yaitu:

a) Menyusun kelengkapan administrasi guru termasuk RPP dan lainnya,

b) Menyiapkan instrumen penelitian untuk guru dan siswa,

c) Menyiapkan format evaluasi pretest dan postest,

d) Menyiapkan sumber belajar berupa materi diskusi, tentang materi yang diajarkan yakni menyusun surat lamaran pekerjaan.

e) Menyiapkan strategi pembelajaran mata pelajaran Bahasa Inggris dengan materi descriptive text dengan strategi melalui menerapkan model pembelajaran Discovery Learning

f) Mengembangkan scenario pembelajaran

\section{Pelaksanaan}

Guru melaksanakan apersepsi, motivasi untuk mengarahkan siswa memasuki KD yang akan dibahas dalam kegiatan pembelajaran mata pelajaran Bahasa Inggris dengan materi descriptive text

a) Guru menjelaskan tujuan pembelajaran yang akan dicapai,

b) Guru menjelaskan materi pembelajaran hari itu dan menjelaskan langkah-langkah kerja yakni tentang model pembelajaran Diuscovery Learning, 
c) Guru mendiskusikan kembali dengan seluruh siswa, bila perlu guru dalam mengajar dapat pengembangan variasi dalam strategi pembelajaran, mata pelajaran Bahasa Inggris.

d) Guru mengadakan tes atau ulangan.

\section{Pengamatan}

a. Observasi (kolaborasi) mengamati kegiatan guru pada saat pembelajaran dan mengamati kegiatan siswa dengan menggunakan instrument pengamatan pembelajaran guru dan siswa,

b. Guru mengevaluasi kegiatannya dengan menggunakan angket guru.

\section{Refleksi}

Hasil evaluasi direfleksikan untuk tindakan selanjutnya dengan pembahasan pada hasil observasi, Kekurangan yang terjadi pada siklus I dikaji lebih lanjut dan diperbaiki pada siklus II akan dilaksanakan langkah-langkah yang sama seperti yang dilakukan pada siklus I.

\section{SIKLUS II}

Pada siklus II Peneliti melakukan tindakan atau refleksi bagi siswa yang belum mencapai hasil maksimal. Kegiatan yang dilakukan pada siklus II sama dengan yang dilakukan pada siklus I (seperti yang telah dijelaskan diatas). Melalui penerapan model pembelajaran Discovery Learning diharapkan dapat meningkatkan hasil belajar siswa sesuai dengan rencana dan program yang telah dirancang.

Hasil yang dicapai pada siklus II adalah hasil akhir dari proses Penelitian Tindakan Kelas ini.

Sebagai ukuran keberhasilan pelaksanaan Penelitian Tindakan Kelas ini adalah siswa yang nilainya mencapai KKM 75 atau bahkan diatas KKM dan prosentase ketuntasan belajar siswa mencapai lebih dari $\mathbf{8 0 \%}$. Jika hasil belum memuaskan akan dilakukan perbaikan di siklus II. Penelitian Tindakan Kelas ini di rancang hanya sampai siklus II untuk itu diharapkan semua siswa yang menjadi subjek dalam Penelitian Tindakan Kelas ini dapat menuntaskan pembelajarannya secara maksimal di siklus II.

\section{Hasil Dan Pembahasan}

Hasil yang dicapai pada siklus I menunjukkan bahwa dengan dilaksanakan model pembelajaran Discovery Learning dapat meningkatkan hasil belajar siswa dari prasiklus ke siklus I. Namun masih ada beberapa hal yang perlu dijelaskan melalui paparan hasil yang dicapai pada siklus I sebagai berikut.

1. Sebanyak 28 siswa yang memperoleh nilai diatas KKM dengan katagori tuntas, dalam belajar bahasa inggris dengan materi Descriptive Text. Siswa telah menunjukkan suatu peningkatan dalam berbicara bahasa inggris, menjelaskan informasi tentang tema materi Descriptive Text, yang dipelajari pada siklus I

2. Sebanyak 8 orang siswa yang mendapatkan nilai dibawah KKM dengan katagori belum tuntas. Dimana dari 8 orang siswa ini belum menunjukkan kemampuan berbicara dalam bahasa ianggris dan belum mampu menyampaikan informasi secara lisan tentang isi materi yaitu Descriptive Text, dengan baik

3. Jumlah nilai rata-rata dibawah KKM yakni 79

4. Tingkat ketercapaian ketuntasan belajar $=78 \%$

5. Siswa yang Belum Tuntas $=22 \%$

6. Peningkatan hasil pembelajaran yang dicapai siswa pada siklus I karena dilaksanakannya model pembelajaran Discovery Learning secara konsisten.

7. Siswa dapat menunjukkan activitas belajarnya lebih tinggi dari prasiklus. Semangan belajar berbicara nampak semakin meningkat.

Pada proses penelitian pada siklus II, terlihat bahwa pelaksanaan penelitian sudah semakin berjalan dengan lancar. Terlihat pada siklus II kendala-kendala pada siklus I sudah dapat diminimalkan. Pencapaian hasil siklus II diatas dapat dijabarkan sebagai berikut. 
1. Sebanyak 36 siswa yang memperoleh nilai diatas KKM dengan katagori tuntas, siswa mampu meningkatkan hasil belajar Bahasa Inggris dengan materi Descriptive Txt secara optimal

2. Sebanyak 36 orang siswa yang telah menuntaskan kegiatan pembelajaran dengan baik.

3. Jumlah nilai rata-rata 80

4. Tingkat ketercapaian ketuntasan belajar $=100 \%$

5. Siswa yang Belum Tuntas $=0 \%$.

Berdasarkan hasil pada siklus I dan II di atas, terlihat bahwa penerapan model pembelajaran Discovery Learning pada mata pelajaran bahasa inggris secara efektif dapat meningkatkan hasil belajar pada aspek berbicara materi descriptive text bagi siswa kelas X. APH.2 Semester Ganjil SMK Negeri 2 Rangkasbitung Tahun Pelajaran 2018/2019.

Hasil penelitian ini sejalan dengan hasil penelitian yang dilakukan oleh Astuti, dkk (2018) dengan judul Penerapan Model Pembelajaran Discovery Learning Untuk Meningkatkan Hasil Belajar Pada Materi Biologi Siswa SMP. Hasil penelitian menunjukkan bahwa pada siklus I rata-rata skor observasi guru adalah 20,5 yang termasuk kriteria cukup, sedangkan rata-rata skor observasi siswa adalah 20 yang termasuk kriteria cukup. Sedangkan pada siklus II ratarata skor observasi guru adalah 29,5 yang termasuk kriteria baik, sedangkan rata-rata skor observasi siswa adalah 27,5 yang termasuk kriteria baik. Data hasil belajar pada siklus I dianalisis berdasarkan kriteria ketuntasan belajar klasikal dan di peroleh persentase ketuntasan belajar klasikal pada siklus I yaitu $54,5 \%$ dengan kriteria belum tuntas dan pada siklus 2 nilai rata-rata siswa meningkat menjadi 84,7\% dengan kriteria tuntas. Kesimpulan dari hasil penelitian menunjukan bahwa penelitian dengan menggunakan model Discovery Learning dapat meningkatkan aktivitas guru, aktivitas siswa dan hasil belajar siswa kelas VII.B SMPN 15 Kota Bengkulu.

\section{Simpulan}

Berdasarkan penelitian yang telah dilakukan, dapat disimpulkan bahwa: penerapan model pembelajaran Discovery Learning dalam pembelajaran mata pelajaran Bahasa Inggris terbukti dengan baik dalam meningkatkan hasil belajar siswa kelas X. APH2 SMK Negeri 2 Rangkasbitung dengan baik

\section{Daftar Pustaka}

Abdurrahman, Mulyono. 2003. Pendidikan Bagi Anak Berkesulitan Belajar. Jakarta: Rineka Cipta.

Arief S. Sadiman. 1986. Asosiasi Pendidikan Nasional. Bandung: Alfabeta

Arikunto, Suharsimi, 1989, Penilaian Program Pendidikan, Proyek Pengembangan LPTK Depdikbud, Dirjen Dikti.

Arikunto, Suharsimi, 1993, Manajemen Mengajar Secara Manusiawi, jakarta rineksa Cipta.

Aristoteles. 202. Manfaat dan Jenis-jenis Media Pembelajaran. Jakarta: Rineka Cipta.

Astuti, Theresia Inovia, dkk. 2018. Penerapan Model Pembelajaran Discovery Learning Untuk Meningkatkan Hasil Belajar Pada Materi Biologi Siswa SMP. Jurnal Pendidikan dan Pembelajaran Biologi Volume 2 Nomor 1.

Bastomi Wibawa. 2001. Media Pembelajaran di SD. Jakarta: Widya Guna.

Basuki Wibawa. 2001. Hakikat Media dan Manfaatnya. Jakarta: Sinema Cipto Karso.

Daryanto. 2010. Fungsi dan Kegunaan Media Pembelajaran. Bandung: Rineka Cipta.

Ido Siti Herawati, Iriaji. 1999. Pendidikan kesenian II. Jakarta: DEPDIKBUD.

Ketut,Drs. 2004. Prinsif Pengembangan Media, Pustekom. Jakarta. 
Mudhofir, Main Sufanti. 2010. Kegunaan Media Pembelajaran. Jakarta: Bumi Aksara.

Mulyono Abdulrahman. 1999. Pendidikan Seni Rupa III. Jakarta: Rineka Cipta.

Nasution. 1986. Didaktik Asas Mengajar. Bandung; Jemmars.

Oemar Hamalik. 2007. Kurikulum dan Pembelajaran. Jkaarta: Bina Aksara.

Pablo Picasso. 1986. Menggambar dan Menggambar Bentuk. Bandung: Alfabeta.

Sapriya. Dkk, 1999, Studi Tentang Media Pembelajaran Nilai dalam mata pelajaran PPKN di SLTP dan SMU Bandung (Laporan penelitian, tidak diterbitkan.)

Surakmad, Winarno. 1982. Pengantar Interaksi Mengajar Belajar: Dasar dan Teknik Metodologi Pengajaran. Bandung. Tarsito.. 